\title{
SISTEM PENDUKUNG KEPUTUSAN PEMILIHAN KARYAWAN TERBAIK PER TRIWULAN PT.CAHAYA FAJAR KALTIM PLTU EMBALUT TANJUNG BATU MENGGUNAKAN METODE SIMPLE ADDITIVE WEIGHTING
}

\author{
Handri Murdianto ${ }^{*}$, , Dyna Marisa Khairina ${ }^{2}$, Heliza Rahmania Hatta ${ }^{3}$ \\ ${ }^{1,2,3}$ Program Studi Ilmu Komputer, FKTI, Universitas Mulawarman \\ Kampus Gunung Kelua Barong Tongkok Samarinda, Kalimantan Timur \\ Email : handri26@gmail.com¹, dyna.ilkom@gmail.com², heliza_rahmania@yahoo.com ${ }^{3}$
}

\begin{abstract}
ABSTRAK
Pengelolaan sumber daya manusia (SDM) dari suatu perusahaan sangat mempengaruhi banyak aspek penentu keberhasilan kerja dari perusahaan tersebut. Salah satu yang terpenting dalam manajemen SDM di suatu perusahaan adalah pemilihan karyawan terbaik secara periodik sehingga yang terpilih akan diberikan penghargaan berupa bonus agar memotivasi karyawan dalam meningkatkan dedikasi dan kinerjanya. Namun pada PT. Cahaya Fajar Kaltim PLTU (Pembangkit Listrik Tenaga Uap) Embalut Tanjung Batu hanya karyawan yang dianggap berprestasi saja yang akan diberikan bonus tersebut. Diperlukan suatu sistem pendukung keputusan (SPK) yang dapat memperhitungkan segala kriteria yang mendukung pengambilan keputusan guna membantu mempermudah proses pengambilan keputusan tersebut. Menerapkan metode Simple Additive Weighting (SAW) dengan menggunakan kriteria-kriteria yang sudah ditetapkan perusahaan yaitu pengetahuan, inisiatif, produktifitas, komunikasi, kerjasama, tanggung jawab, dan kehadiran. Sistem yang dihasilkan adalah nilai perhitungan pemilihan karyawan terbaik per triwulan dengan metode Simple Additive Weighting (SAW) dan rekomendasi karyawan terbaik per triwulannya.
\end{abstract}

Kata Kunci : Sistem Pendukung Keputusan, Karyawan, Kriteria, Simple Additive Weighting (SAW).

\section{PENDAhuluan}

Dalam suatu perusahaan sumber daya manusia (SDM) berperan sangat penting bagi kelangsungan perusahaan tersebut sehingga gaji merupakan hal wajib yang diberikan perusahaan kepada karyawannya, disamping gaji biasanya perusahaan memberikan penghargaan berupa bonus kepada karyawannya, hal ini untuk memotivasi para karyawannya agar dapat bekerja lebih giat lagi. Pemberian bonus merupakan salah satu cara yang digunakan oleh perusahaan sebagai sebuah bentuk penghargaan kepada karyawan yang kinerjanya selama ini dianggap memuaskan oleh perusahaan.

Begitu juga dengan PT. Cahaya Fajar Kaltim PLTU (Pembangkit Listrik Tenaga Uap) Embalut Tanjung Batu yang merupakan perusahaan patungan perusda Kalimantan Timur dengan Jawa Pos Group yang dulu dipimpin Dahlan Iskan menerapkan hal yang sama pada karyawannya, tetapi yang hanya dianggap berprestasi saja yang akan diberikan bonus triwulan oleh perusahaan tersebut. Seharusnya ada penilaian berupa karyawan terbaik per triwulan yang

menjadi rujukan dalam memberikan bonus kepada karyawan yang dinilai dari kriteria-kriteria yang merupakan perusahaan patungan perusda Kalimantan Timur dengan Jawa Pos Group yang dulu dipimpin Dahlan Iskan menerapkan hal yang sama pada karyawannya, tetapi yang hanya dianggap berprestasi saja yang akan diberikan bonus triwulan oleh perusahaan tersebut. Seharusnya ada penilaian berupa karyawan terbaik per triwulan yang menjadi rujukan dalam memberikan bonus kepada karyawan yang dinilai dari kriteria-kriteria yang ditetapkan oleh perusahaan, sehingga semua karyawan yang bekerja pada PLTU Embalut Tanjung Batu berpeluang sama untuk mendapatkan bonus tersebut. Oleh karena itu diperlukan suatu sistem pendukung keputusan (SPK) yang dapat memperhitungkan segala kriteria yang mendukung pengambilan keputusan guna membantu mempermudah proses pengambilan keputusan tersebut.

Untuk menunjang sistem keputusan tersebut maka penulis menggunakan suatu metode yang dapat digunakan untuk membantu sistem keputusan tersebut. Metode yang dipakai dalam pendukung keputusan pemilihan karyawan terbaik per triwulan pada PT. Cahaya Fajar Kaltim adalah metode Simple Additive Weighting. Metode Simple Additive Weighting sering juga dikenal istilah metode pejumlahan terbobot, konsep dasar metode Simple Additive Weighting adalah mencari pejumlahan terbobot dari rating kinerja pada setiap alternatif pada semua atribut. Metode Simple Addtive Weighting membutuhkan proses normalisasi matriks keputusan (X) ke suatu skala yang dapat diperbandingkan dengan semua rating 
alternatif yang ada. Metode ini dipilih karena mampu menyeleksi alternatif terbaik dari sejumlah alternatif, dalam hal ini alternatif yang dimaksud yaitu karyawan terbaik berasarkan kriteria - kriteria yang ditentukan. Penelitian dilakukan dengan mencari nilai bobot untuk setiap atribut, kemudian proses perangkingan yang akan menentukan alternatif yang optimal, yaitu karyawan terbaik. Dengan metode tersebut diharapkan penilaian akan lebih akurat. Karena, didasarkan pada nilai kriteria yang sudah ditentukan sehingga akan mendapatkan hasil yang lebih akurat terhadap siapa yang dipilih menjadi karyawan terbaik per triwulan.

\section{TINJAUAN PUSTAKA}

\subsection{Sistem Pendukung Keputusan}

Sistem pendukung keputusan (SPK) atau decision support system (DSS) adalah suatu sistem yang berkerja secara otomatis yang bertujuan membantu para user untuk mengoptimalkan data yang ada untuk memilih atau menentukan suatu masalah yang timbul karena banyaknya faktorfaktor yang mempengaruhi pemilihan keputusan yang sesuai dan cocok dengan kriteria yang diinginkan. Ada juga yang mendefinisikan SPK merupakan suatu pendekatan untuk pengambilan keputusan. Sistem pendukung keputusan menggunakan data, memberikan antarmuka pengguna yang mudah, dan dapat menggabungkan pengambil keputusan [5].

\subsection{Karyawan}

Karyawan adalah setiap orang yang menyediakan jasa (baik dalam bentuk pikiran maupun dalam bentuk tenaga) dan mendapatkan balas jasa ataupun kompensasi yang besarannya telah ditentukan terlebih dahulu [2].

Karyawan merupakan setiap penduduk yang masuk ke dalam usia kerja (berusia di rentang 15 hingga 64 tahun), atau jumlah total seluruh penduduk yang ada pada sebuah negara yang memeproduksi barang dan jasa jika ada permintaan akan tenaga yang mereka produksi, dan jika mereka mau berkecimpung atau berpartisipasi dalam aktivitas itu [4].

\subsection{Metode Simple Additive Weighting}

Metode Simple Additive Weighting (SAW) sering juga dikenal dengan istilah metode penjumlahan terbobot. Konsep dasar metode SAW adalah mencari penjumlahan bobot dari rating kinerja pada setiap alternatif pada semua atribut. Langkah-langkah dalam metode SAW [1][3] :

1. Membuat matrik keputusan $\mathrm{Z}$ berukuran $\mathrm{m} x \mathrm{n}$, dimana $\mathrm{m}=$ alternatif yang akan dipilih dan $\mathrm{n}=$ kriteria.

2. Memberikan nilai $\mathrm{x}$ setiap alternatif (i) pada setiap kriteria (j) yang sudah ditentukan, dimana $\mathrm{i}=1,2, \ldots \mathrm{m}$ dan $\mathrm{j}=1,2, \ldots \mathrm{n}$ pada matriks keputusan $\mathrm{Z}$,

$\left.Z=\left[\begin{array}{cccc}X_{11} & X_{12} & \cdots & X_{1 j} \\ \vdots & \vdots & \ddots & \vdots \\ X_{i 1} & X_{i 2} & \cdots & X_{i j}\end{array}\right]\right]$

3. Memberikan nilai bobot preferensi (W) oleh pengambil keputusan untuk masing-masing kriteria yang sudah ditentukan.

$\mathrm{W}=\left[\mathrm{W}_{1}, \mathrm{~W}_{2}, \mathrm{~W}_{3}, \ldots . . \mathrm{W}_{\mathrm{j}}\right] \quad(2)$

4. Melakukan normalisasi matriks keputusan $\mathrm{Z}$ dengan cara menghitung nilai rating kinerja ternormalisasi $\left(r_{i j}\right)$ dari alternatif $A_{1}$ pada atribut $\mathrm{C}_{\mathrm{j}}$.

$r_{i j}=\left\{\begin{array}{l}\frac{X_{i j}}{M A X_{i}\left(X_{i j}\right)} j i k a \text { j adalah atribut keuntungan } \\ \frac{M_{I N}\left(X_{i j}\right)}{X_{i j}} j i k a j \text { adalah atribut biaya }\end{array}\right.$

Dengan ketentuan :

a. Atribut keuntungan apabila atribut banyak memberikan keuntungan bagi pengambil keputusan, sedangkan atribut biaya merupakan atribut yang banyak memberikan pengeluaran jika nilainya semakin besar bagi pengambil keputusan.

b. Apabila berupa atribut keuntungan maka nilai $\left(\mathrm{X}_{\mathrm{ij}}\right)$ dari setiap kolom atribut dibagi dengan nilai (MAX $\mathrm{x}_{\mathrm{ij}}$ ) dari tiap kolom, sedangkan untuk atribut biaya, nilai (MIN $\mathrm{x}_{\mathrm{ij}}$ ) dari tiap kolom atribut dibagi dengan nilai $\left(\mathrm{x}_{\mathrm{ij}}\right)$ setiap kolom.

5. Hasil dari rating kinerja ternormalisasi $\left(\mathrm{r}_{\mathrm{ij}}\right)$ membentuk matriks ternormalisasi $(\mathrm{N})$

$N=\left[\left[\begin{array}{cccc}r_{11} & r_{12} & \cdots & r_{1 j} \\ \vdots & \vdots & \ddots & \vdots \\ r_{i 1} & r_{i 2} & \cdots & r_{i j}\end{array}\right]\right]$

6. Melakukan proses perangkingan dengan cara mengalikan matriks ternormalisasi dengan nilai bobot preferensi (W).

7. Menentukan nilai preferensi untuk setiap alternatif $\left(\mathrm{V}_{\mathrm{i}}\right)$ dengan cara menjumlahkan hasil kali antara matriks ternormalisasi $(\mathrm{N})$ dengan nilai bobot preferensi (W).

$V_{i}=\sum_{j=1}^{n} W_{j} r_{i j}$

Maka nilai $\mathrm{V}_{\mathrm{i}}$ yang lebih besar mengindikasikan bahwa alternatif $A_{1}$ merupakan alternatif terbaik.

\section{HASIL DAN PEMBAHASAN}

\subsection{Perencanaan Sistem}

Pada tahap perencanaan ini peneliti akan melakukan pengumpulan data-data serta informasi melalui beberapa literatur mengenai metode yang digunakan, aplikasi yang digunakan untuk membangun aplikasi, dan mencari data-data yang diperlukan untuk membangun aplikasi ini. 
Penulis melakukan survei langsung ke kantor PT. Cahaya Fajar Kaltim PLTU Embalut Tanjung Batu untuk memperoleh data kriteria-kriteria dan data karyawan. Adapun kriteria-kriteria dan nilai bobot yang menjadi bahan perhitungan atau pertimbangan dijabarkan pada tabel 1 .

Tabel 1. Kriteria dan Nilai Crips

\begin{tabular}{|c|c|}
\hline Keterangan & Penjabaran \\
\hline \multirow{4}{*}{$\begin{array}{l}\text { Pengetahuan Pekerjaan } \\
\text { (C1) }\end{array}$} & Kurang Sekali $=1$ \\
\hline & Kurang $=2$ \\
\hline & Baik $=3$ \\
\hline & Baik Sekali $=4$ \\
\hline \multirow{4}{*}{ Inisiatif Pekerjaan (C2) } & Tidak Pernah $=1$ \\
\hline & Kadang-kadang $=2$ \\
\hline & Sering $=3$ \\
\hline & Selalu $=4$ \\
\hline \multirow{4}{*}{$\begin{array}{l}\text { Produktifitas Pekerjaan } \\
\text { (C3) }\end{array}$} & Kurang Sekali = 1 \\
\hline & Kurang $=2$ \\
\hline & Baik $=3$ \\
\hline & Baik Sekali $=4$ \\
\hline \multirow{4}{*}{ Komunikasi (C4) } & Tidak Pernah $=1$ \\
\hline & Kadang-kadang $=2$ \\
\hline & Sering $=3$ \\
\hline & Selalu $=4$ \\
\hline \multirow{4}{*}{ Kerjasama (C5) } & Tidak Pernah = 1 \\
\hline & Kadang-kadang $=2$ \\
\hline & Sering $=3$ \\
\hline & Selalu $=4$ \\
\hline \multirow{4}{*}{ Tanggung Jawab (C6) } & Kurang Sekali $=1$ \\
\hline & Kurang = 2 \\
\hline & Baik $=3$ \\
\hline & Baik Sekali $=4$ \\
\hline \multirow{4}{*}{ Kehadiran (C7) } & Tidak Pernah = 1 \\
\hline & Kadang-kadang $=2$ \\
\hline & Sering $=3$ \\
\hline & Selalu $=4$ \\
\hline
\end{tabular}

Kemudian ditetapkan nilai bobot kriteria (W) pada tabel 2 .

Tabel 2. Penentuan Nilai W

\begin{tabular}{ccc}
\hline Kriteria & Range (\%) & Bobot \\
\hline C1 & 20 & 0.2 \\
C2 & 13 & 0.13 \\
C3 & 12 & 0.12 \\
C4 & 11 & 0.11 \\
C5 & 14 & 0.14 \\
C6 & 15 & 0.15 \\
C7 & 15 & 0.15 \\
\hline
\end{tabular}

\subsection{Perancangan Sistem}

Pada sistem pemilihan ini, admin dapat merubah bobot kriteria-kriteria sewaktu-waktu ada perubahan nilai prioritas kriteria yang ditetapkan oleh perusahaan. Dalam perancangan sistem ini digunakan dua diagram Unified Modeling
Language (UML) yaitu use case diagram mengambarkan aktor melakukan apa dalam sistem dan activity diagram yang menggambarkan aktivitas sistem bukan apa yang dilakukan aktor, jadi aktivitas yang dapat dilakukan oleh sistem. Perancangan usecase diagram merupakan tahap awal dan utama dalam proses pengembangan sistem, dimana dalam diagram ini menjelaskan bagaimana sisitem ini bekerja, fitur-fitur apa saja yang disediakan oleh sistem.

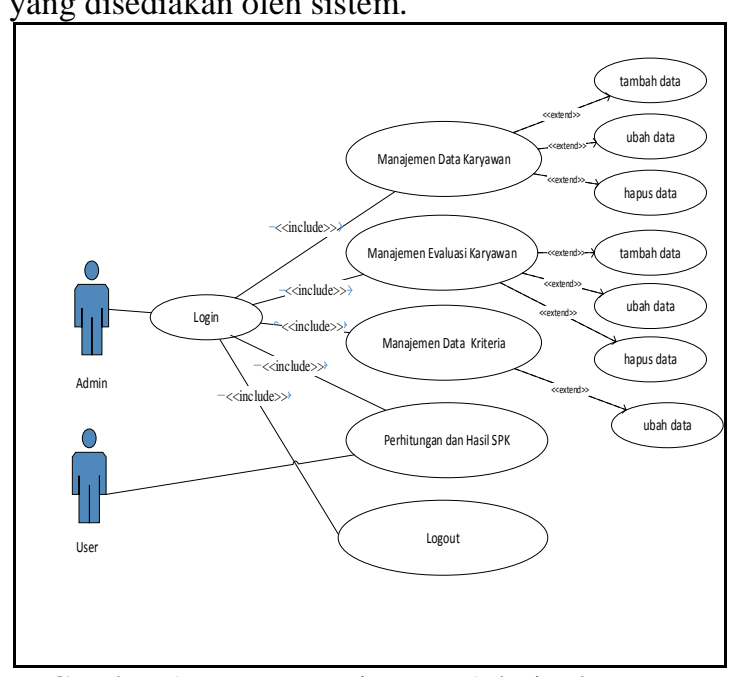

Gambar 1. Use case Diagram Admin dan User Terlihat pada gambar 1. Admin berperan dalam melakukan manajemen data karyawan dalam aksi ini admin dapat menambahkan data karyawan, merubah data karyawan, dan menghapus data karyawan. Admin berperan dalam evaluasi karyawan, dalam aksi ini admin juga beperan dalam manajemen data kriteria dalam aksi ini admin dapat mengubah data kriteria. Sedangkan User berperan hanya melihat halaman hasil SPK, dalam hal ini agar pemilihan alternatif terlihat lebih transparan.

\subsection{Implementasi Sistem}

Perancangan interface dilakukan setelah perancangan-perancangan logika dan alur sistem utama telah diselesaikan, dalam tahapan ini dirancang antarmuka yang akan ditampilkan oleh sistem kepada pengguna dan admin.

Halaman interface atau antarmuka Sistem Pemilihan Karyawan Terbaik merupakan halaman yang berfungsi sebagai tampilan halaman Hasil pencarian dan Hasil SPK. Dalam halaman ini tampilan dibuat sederhana mungkin dikarenakan user hanya berperan melihat pencarian hasil SPK. Ditahapan ini user saat menggunakan sistem adalah yaitu user hanya bisa memilih tahun dan triwulan yang ingin dicari. Halaman bisa dilihat pada gambar 2 . 


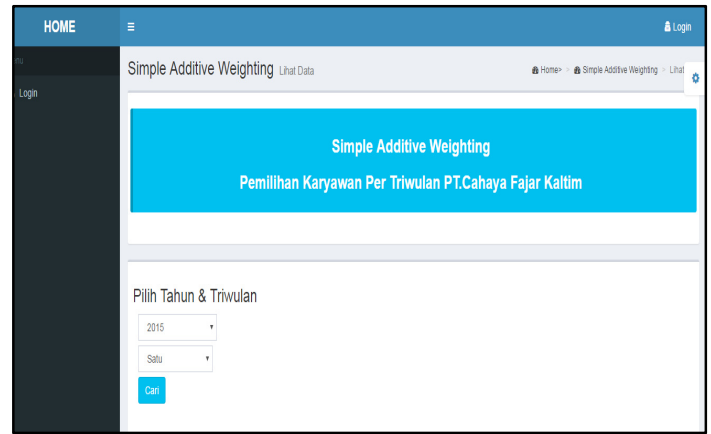

Gambar 2. Halaman Hasil pencarian SPK

Halaman login admin merupakan halaman awal admin untuk masuk kedalam menu-menu pada sistem pemilihan hotel ini, tetapi sebelum itu admin harus menginputkan username dan password sebagai pengamanan sistem dalam pengelolaan data-data sistem ini. Halaman login admin bisa dilihat pada gambar 3 .

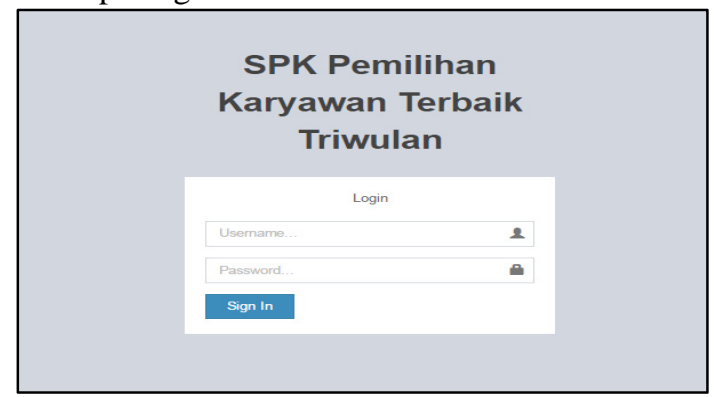

Gambar 3. Halaman Log in Admin

Setelah melalui proses login, admin akan masuk ke halaman menu admin. Di dalam halaman menu admin terdapat beberapa menu pilihan pengelolaan data antara lain total user, menu total bobot, menu karyawan, menu evaluasi, menu sistem pendukung keputusan SAW. Halaman home admin bisa dilihat pada gambar 4 .

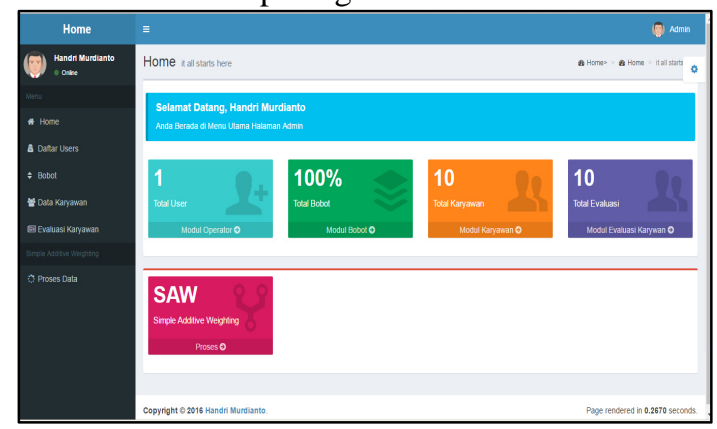

Gambar 4. Halaman Home admin

Beberapa tahapan saat akan menggunakan sistem ini adalah pertama admin memasukkan nilai bobot dari masing-masing kriteria. Nilai kriteria harus genap $100 \%$ jika tidak sistem tidak akan memproses ketahapan selanjutnya. Halaman bobot kriteria dapat dilihat pada gambar 5 .

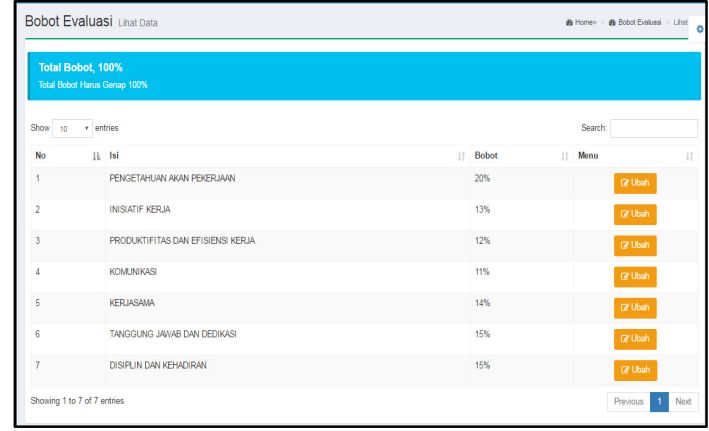

Gambar 5. Halaman bobot Kriteria

Tahapan kedua admin memasukan data karyawan yang berisi NIK, Nama, Departemen, Jabatan, dan Jenis Kelamin pada form data karyawan yang bisa dilihat pada gambar 6 .

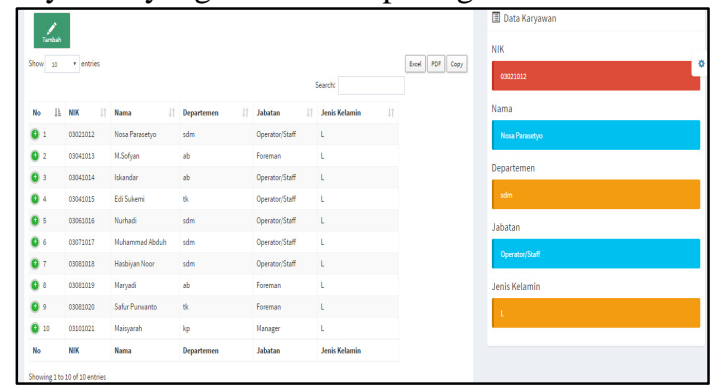

Gambar 6. Halaman Data karyawan

Tahapan Ketiga admin memasukkan data nilai evaluasi masing-masing karyawan yang data karyawannya sudah dimasukkan sebelumnya pada tahap kedua. Penjelasan dapat dilihat pada gambar 7.

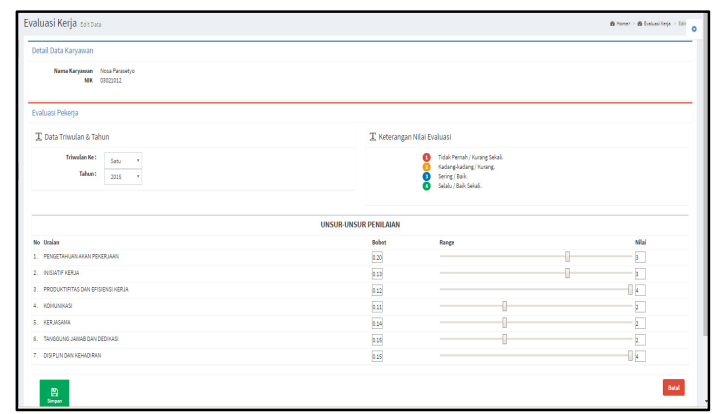

Gambar 7. Halaman Nilai Evaluasi Karyawan

Setelah tahapan ketiga selesai daftar evaluasi dapat dilihat pada form evaluasi karyawan, pada form ini data bisa diubah jika ada kesalahan dalam memasukan nilai evaluasi. Halaman evaluasi karyawan dapat dilihat pada gambar 8 .

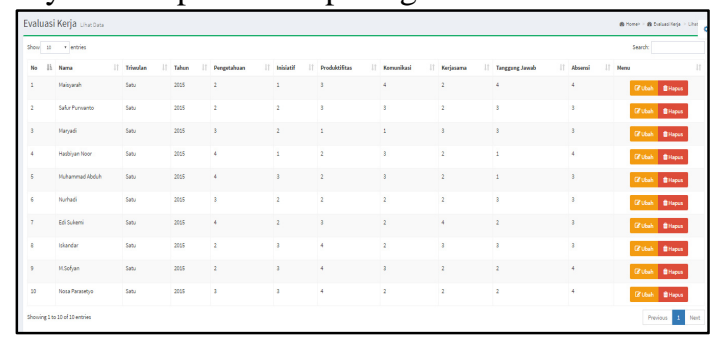

Gambar 8. Halaman Evaluasi Karyawan 
Setelah semua data sudah dimasukkan dan di validasi oleh admin. Dilanjutkan ke proses terakhir yaitu halaman Proses Data. Pada halaman ini data akan memproses hasil masukkan data kriteria dan data karyawan beserta nilai evaluasi periode triwulan dan tahun yang dimasukkan oleh admin. Output data dapat dilihat pada gambar 9.

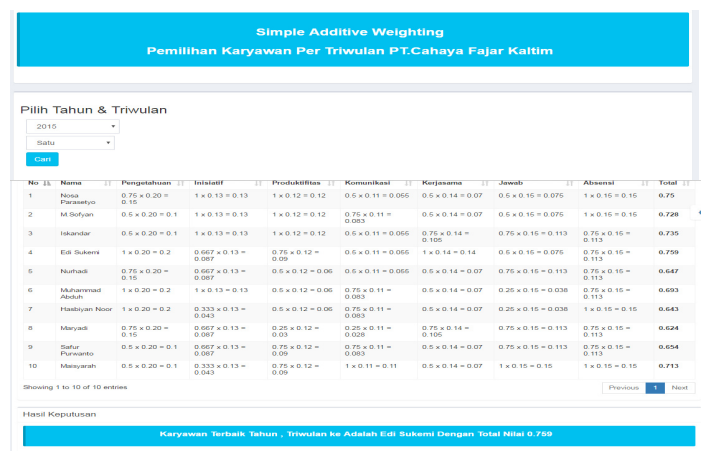

Gambar 9. Halaman Hasil Proses SPK

\subsection{Pengujian Metode SAW}

Tahap awal pengujian pada sistem ini memasukan data kriteria yang sudah ditetapkan perusahaan sebelumnya, penjelasan nilai bobot kriteria dapat dijelaskan dengan rincian tabel 3.

Tabel 3. Tabel Bobot Kriteria

\begin{tabular}{clc}
\hline Kriteria & \multicolumn{1}{c}{ Keterangan } & Bobot \\
\hline C1 & $\begin{array}{l}\text { Pengetahuan akan } \\
\text { pekerjaan }\end{array}$ & $20 \%$ \\
C2 & Inisatif Kerja & $13 \%$ \\
C3 & $\begin{array}{l}\text { Produktifitas Dan } \\
\text { Efisensi Kerja }\end{array}$ & $12 \%$ \\
C4 & Komunikasi & $11 \%$ \\
C5 & Kerjasama & $14 \%$ \\
C6 & Tanggung Jawab & $15 \%$ \\
C7 & Disiplin dan & $15 \%$ \\
& Kehadiran & 10
\end{tabular}

Pengujian untuk diambil sampel 10 data karyawan yang akan dicalonkan sebagai karyawan terbaik periode triwulan satu tahun 2016 dengan daftar karyawan yang tercantum dalam tabel 4.

Tabel 4. Daftar Karyawan dan Nilai Evaluasi

\begin{tabular}{|c|c|c|c|c|c|c|c|c|c|}
\hline 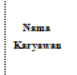 & Tririulahs & Tabm & Pegentaban & Intiatiatif & Protadk tifits: & $\begin{array}{c}\text { Komumalk } \\
\text { sia }\end{array}$ & Kärjezsms & 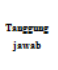 & 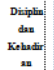 \\
\hline $\begin{array}{l}\text { Nosa } \\
\text { Prasastyo }\end{array}$ & 1 & 2016 & Bsilk & Baile & Bsilk sekali & Kurang & Kurang & Kurang & $\begin{array}{l}\begin{array}{c}\text { Baik } \\
\text { sekal }\end{array} \\
\end{array}$ \\
\hline Mr.Sofyan & 1 & 2016 & Kurang & Baik & Baik & Bailk & Kurang & Kurang & $\begin{array}{r}\text { Baik } \\
\text { Selkali }\end{array}$ \\
\hline Tikandar & 1 & 2016 & Kurang & Bailk & Baik sekali & Kurang & Baik & Baik & Baik \\
\hline Edi sulkemi & 1 & 2016 & Bailk Sekali & Kurang & Bailk & Kurang & $\begin{array}{l}\text { Baik } \\
\text { Sekali }\end{array}$ & Kurang & \\
\hline Nurhadi & 1 & 2016 & Baik & Kurang & Kurang & Kurang & Kurang & Baik & Baik \\
\hline $\begin{array}{l}\text { "Muhammma } \\
\text { a Abduh }\end{array}$ & 1 & 2016 & Bsaik Sekali & Baik & urang & Bsik & Kurang & $\begin{array}{l}\text { Kurang } \\
\text { Sekali }\end{array}$ & Baik \\
\hline $\begin{array}{l}\text { Hasbiyan } \\
\text { Noor }\end{array}$ & 1 & 2016 & Baik Sekali & $\begin{array}{l}\text { Kurang } \\
\text { Sekali }\end{array}$ & Kurang & aik & Kurang & $\begin{array}{l}\text { Kurang } \\
\text { Seksali }\end{array}$ & $\begin{array}{l}\text { Baik } \\
\text { Selkali }\end{array}$ \\
\hline Marysadi & 1 & 2016 & Baik & Kurang & $\begin{array}{l}\text { Kurang } \\
\text { Sekali }\end{array}$ & $\begin{array}{c}\text { Kurang } \\
\text { Sekali }\end{array}$ & Bsilk & Bsilk & Bail \\
\hline $\begin{array}{l}\text { Safurur } \\
\text { Purwanto }\end{array}$ & 1 & 2016 & Kurang & Kurang & Bailk & Baik & Kurang & Bsilk & Baik \\
\hline "Maisyarah & 1 & 2016 & Kurang & $\begin{array}{l}\text { Kurang } \\
\text { Sekali }\end{array}$ & Bailk & $\begin{array}{c}\text { Baik } \\
\text { Sekali }\end{array}$ & Kurang & $\begin{array}{c}\text { Baik } \\
\text { Sekali }\end{array}$ & $\begin{array}{l}\text { Bailk } \\
\text { Selkali }\end{array}$ \\
\hline
\end{tabular}

Tahapan selanjutnya admin memasukkan data karyawan serta nilai evaluasi masing-masing karyawan yang akan dinilai oleh sistem dan penentuan nilai ini menggunakan bilangan fuzzy yang dapat dikonversikan ke dalam bilangan crips dengan ketentuan pada tabel 5.

\begin{tabular}{cc}
\multicolumn{2}{c}{ Tabel 5. Tabel Nilai Crips } \\
\hline Bilangan Fuzzy & Nilai \\
\hline Tidak Pernah/ Kurang Sekali & 1 \\
Kadang-kadang/ Kurang & 2 \\
Sering/ Baik & 3 \\
Selalu/ Baik Sekali & 4 \\
\hline
\end{tabular}

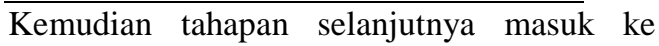
proses normalisasi yang dapat dilihat pada tabel 6 .

Tabel 6. Tabel Normalisai Kriteria

\begin{tabular}{|l|c|c|c|c|c|c|c|}
\hline \multicolumn{1}{|c|}{ Nama Karyawan } & C1 & C2 & C3 & C4 & C5 & C6 & C7 \\
\hline Nosa Prasetyo & 3 & 3 & 4 & 2 & 2 & 2 & 4 \\
\hline M.Sofyan & 2 & 3 & 4 & 3 & 2 & 2 & 4 \\
\hline Iskandar & 2 & 3 & 4 & 2 & 3 & 3 & 3 \\
\hline Edi sukemi & 4 & 2 & 3 & 2 & 4 & 2 & 3 \\
\hline Nurhadi & 3 & 2 & 2 & 2 & 2 & 3 & 3 \\
\hline Muhammad Abduh & 4 & 3 & 2 & 3 & 2 & 1 & 3 \\
\hline Hasbiyan Noor & 4 & 1 & 2 & 3 & 2 & 1 & 4 \\
\hline Maryadi & 3 & 2 & 1 & 1 & 3 & 3 & 3 \\
\hline Safur Purwanto & 2 & 2 & 3 & 3 & 2 & 3 & 3 \\
\hline Maisyarah & 2 & 1 & 3 & 4 & 2 & 4 & 4 \\
\hline
\end{tabular}

Setelah kriteria dinormalisasi tahap selanjutnya adalah melakukan normalisasi matriks keputusan dengan cara menghitung nilai rating kinerja ternormalisasi $\left(\mathrm{r}_{\mathrm{ij}}\right)$ dari alternatif $\mathrm{A}_{\mathrm{i}}$ pada atribut $\mathrm{C}_{\mathrm{j}}$. Dengan ketentuan rumus dibawah ini :

$$
r_{i j}\left\{\frac{X_{i j}}{M A X_{i}\left(X_{i j}\right)}\right\}
$$

Tabel 7. Normalisasi Matriks

\begin{tabular}{|l|c|c|c|c|c|c|c|}
\hline Nama Karyawan & C1 & C2 & C3 & C4 & C5 & C6 & C7 \\
\hline Nosa Prasetyo & 0.75 & 1 & 1 & 0.5 & 0.5 & 0.5 & 1 \\
\hline M.Sofyan & 0.5 & 1 & 1 & 0.75 & 0.5 & 0.5 & 1 \\
\hline Iskandar & 0.5 & 1 & 1 & 0.5 & 0.75 & 0.75 & 0.75 \\
\hline Edi sukemi & 1 & 0.667 & 0.75 & 0.5 & 0.75 & 0.75 & 0.75 \\
\hline Nurhadi & 0.75 & 0.667 & 0.5 & 0.5 & 0.5 & 0.25 & 0.75 \\
\hline Muhammad Abduh & 1 & 1 & 0.5 & 0.75 & 0.5 & 0.25 & 0.75 \\
\hline Hasbiyan Noor & 1 & 0.33 & 0.5 & 0.75 & 0.5 & 0.25 & 0.75 \\
\hline Maryadi & 0.75 & 0.667 & 0.25 & 0.25 & 0.75 & 0.75 & 0.75 \\
\hline Safur Purwanto & 0.5 & 0.667 & 0.75 & 0.75 & 0.5 & 0.75 & 0.75 \\
\hline Maisyarah & 0.5 & 0.333 & 0.75 & 1 & 0.5 & 1 & 1 \\
\hline
\end{tabular}

Setelah tahapan normalisasi, selanjutnya menentukan nilai bobot preferensi (W) oleh pengambil keputusan untuk masing-masing kriteria yang sudah ditentukan. Tahapan ini dapat dilihat pada gambar 4.12. Dilanjutkan dengan menentukan nilai preferensi (Vi) dengan cara menjumlahkan hasil kali antara matriks ternomalisasi $(\mathrm{N})$ dengan nilai bobot preferensi (W). Dengan rumus dibawah berikut : 


$$
\sum_{j=1}^{n} W_{j} r_{i j}
$$

Maka nilai Vi yang lebih besar mengidentifikasi bahwa alternatif A1 merupakan alternatif terbaik.

Bobot Preferensi (W) :

Pengetahuan akan pekerjaan $\quad: 0.20$

Inisatif Kerja $\quad: 0.13$

Produktifitas Dan Efisensi Kerja : 0,12

Komunikasi $\quad: 0.11$

Kerjasama $\quad: 0.14$

Tanggung Jawab $\quad: 0.15$

Disiplin dan Kehadiran $\quad: 0.15$

Berikut adalah hasil akhir dari tahapan proses SAW yang terlihat pada tabel 8 .

Tabel 8. Tabel Nilai Alternatif (V)

\begin{tabular}{|l|c|c|c|c|c|c|c|c|}
\hline Nama Karyawan & $\mathbf{C l}$ & $\mathbf{C 2}$ & $\mathbf{C 3}$ & $\mathbf{C 4}$ & $\mathbf{C 5}$ & $\mathbf{C 6}$ & $\mathbf{C 7}$ & Total \\
\hline Nosa Prasetyo & 0.20 & 0.13 & 0.12 & 0.055 & 0.07 & 0.075 & 0.15 & $\mathbf{0 . 7 5}$ \\
\hline M.Sofyan & 0.1 & 0.13 & 0.12 & 0.083 & 0.07 & 0.075 & 0.15 & $\mathbf{0 . 7 2 8}$ \\
\hline Iskandar & 0.1 & 0.13 & 0.12 & 0.055 & 0.105 & 0.113 & 0.113 & $\mathbf{0 . 7 3 5}$ \\
\hline Edi sukemi & 0.2 & 0.087 & 0.09 & 0.055 & 0.14 & 0.075 & 0.113 & $\mathbf{0 . 7 5 9}$ \\
\hline Nurhadi & 0.15 & 0.087 & 0.06 & 0.055 & 0.07 & 0.038 & 0.113 & $\mathbf{0 . 6 4 7}$ \\
\hline Muhammad Abduh & 0.2 & 0.13 & 0.06 & 0.083 & 0.07 & 0.038 & 0.113 & $\mathbf{0 . 6 9 3}$ \\
\hline Hasbiyan Noor & 0.2 & 0.043 & 0.06 & 0.83 & 0.07 & 0.38 & 0.15 & $\mathbf{0 . 6 4 3}$ \\
\hline Maryadi & 0.15 & 0.087 & 0.03 & 0.028 & 0.105 & 0.113 & 0.113 & $\mathbf{0 . 6 2 4}$ \\
\hline Safur Purwanto & 0.1 & 0.043 & 0.09 & 0.11 & 0.07 & 0.15 & 0.15 & $\mathbf{0 . 6 5 4}$ \\
\hline Maisyarah & 0.5 & 0.333 & 0.75 & 1 & 0.5 & 1 & 1 & $\mathbf{0 . 7 1 3}$ \\
\hline
\end{tabular}

\section{KESIMPULAN DAN SARAN}

\subsection{Kesimpulan}

Berdasarkan penelitian yang telah dilakukan oleh penulis, dapat diperoleh beberapa kesimpulan, diantaranya:

1. Sistem Pemilihan Karyawan Terbaik membantu pengambil keputusan dalam masalah pemilihan karyawan terbaik secara cepat berdasarkan kriteria yang ditetapkan.

2. Metode Simple Additive Weighting sangat cocok digunakan untuk menentukan nilai tertinggi dari hasil evaluasi karyawan.

3. Penentuan nilai bobot kriteria sangat mempengaruhi nilai hasil perhitungan Simple Additive Weighting.

\subsection{Saran}

Beberapa saran yang berguna dalam pengembangan sistem lanjutan yaitu antara lain:

1. Untuk penelitian selanjutnya diharapkan metode Simple Additive Weighting bisa di kombinasikan dengan metode lain untuk menentukan besar bonus dari pemilihan karyawan terbaik ini.

2. Diharapkan penelitian selanjutnya dikembangkan dalam bentuk mobile berbasis Android atau sistem operasi sejenisnya.

\section{TINJAUAN PUSTAKA}

[1]. Fishburn,P.C.1967. Additive Utilities with Incomplete Product Set: Application to Priorities and Assignments.

[2]. Hasibuan, Malayu S.P. 2002. Manajemen Sumber Daya Manusia. Jakarta: Bumi Aksara.

[3]. MacCrimmon,K.R.1968. Decision Making among Multiple Atribut Alternatives: a Survey and Consolidated Approach.

[4]. Subri, M. 2002. Ekonomi Sumber Daya Manusia. Jakarta: Raja Grafindo Persada

[5]. Turban, Efraim. 2005. Decision Support Systems and Intelligent System. Yogyakarta : Andi 